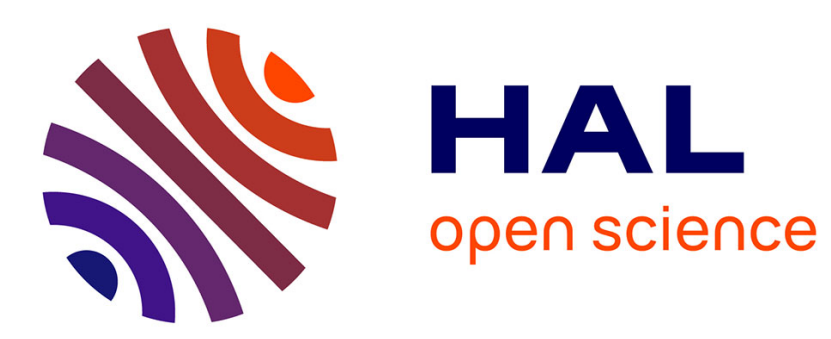

\title{
Robust position control of an electropneumatic system using second order sliding mode
}

\author{
Mohamed Smaoui, Xavier Brun, Daniel Thomasset
}

\section{To cite this version:}

Mohamed Smaoui, Xavier Brun, Daniel Thomasset. Robust position control of an electropneumatic system using second order sliding mode. IEEE ISIE, May 2004, Ajaccio, France. pp.429-434 vol. 1, 10.1109/ISIE.2004.1571846 . hal-02064132

\section{HAL Id: hal-02064132 \\ https://hal.science/hal-02064132}

Submitted on 20 Mar 2019

HAL is a multi-disciplinary open access archive for the deposit and dissemination of scientific research documents, whether they are published or not. The documents may come from teaching and research institutions in France or abroad, or from public or private research centers.
L'archive ouverte pluridisciplinaire HAL, est destinée au dépôt et à la diffusion de documents scientifiques de niveau recherche, publiés ou non, émanant des établissements d'enseignement et de recherche français ou étrangers, des laboratoires publics ou privés. 


\title{
Robust Position Control of an Electropneumatic System Using Second Order Sliding Mode
}

\author{
M. SMAOUI, X. BRUN and D. THOMASSET \\ Laboratoire d'Automatique Industrielle, INSA de Lyon, Bât Antoine de SAINT-EXUPERY, \\ 25, avenue Jean Capelle, 69621Villeurbanne Cedex, France, \\ http://www-lai.insa-lyon.fr/ \\ e-mail:mohamed.smaoui@insa-lyon.fr
}

\begin{abstract}
First order sliding mode control is an important robust control approach. For the class of systems to which it applies, first order sliding mode controller provides a systematic approach to the problem of maintaining stability and consistent performance in the face of modeling imprecision. On the other hand, the chattering phenomenon is one of the major problems in first order sliding mode control.

This paper introduces a second order sliding mode control approach in the context of position control of an electropneumatic system. The main objective is to demonstrated through this approach the undesired chattering phenomenon can be avoided while retaining the same robustness of first order sliding mode control.
\end{abstract}

Index Terms-2-Sliding, Tracking, Electropneumatic system, Experiment

\section{Nomenclature}

$k$

$\mathrm{M}$

$p$

$q_{m}$

$r$

$S$

$\mathrm{T}$

$V$

$\mathrm{y}, \mathrm{v}, \mathrm{a}$

$\varphi($.

$\psi($.

$l$

Subscript

ext external

$D \quad$ dead volume

$S \quad$ supply

$N \quad$ chamber $\mathrm{N}$

$P \quad$ chamber $\mathrm{P}$

d desired

\section{INTRODUCTION}

The sliding-mode controller (SMC) design is an attractive approach. The primary characteristic of SMC is that the feedback signal is discontinuous, switching on one or several manifolds in the state-space. When the state trajectory crosses each discontinuity surfaces in the state- space, the structure of the feedback system and hence its dynamics will be altered. Under certain circumstances, all motions in the neighborhood of a manifold are directed towards the manifold and, thus, a sliding motion on a predefined subspace of the state-space is established in which the system state repeatedly crosses the switching surfaces. This mode has useful invariance properties even in the presence of uncertainties in the plant model and, therefore, is a good candidate for robust tracking control of uncertain nonlinear systems [1][2] [3][4].

Specific drawback presented by the classical sliding mode techniques is the chattering phenomenon [5]. The chattering phenomenon is generally perceived as motion, which oscillates about the sliding manifold. In order to overcome this drawback, a research activity aimed at finding a continuous control action, robust against uncertainties, guaranteeing the attainment of the same control objective of the standard sliding mode approach has been carried out in recent years. The results algorithms, turned out to belong to the class of second order sliding mode control algorithms [6] [7] In literature, many algorithms have been presented [8] [9][10].

The relative degree of the sliding variable is one with respect to the input, which in the case of position control of electropneumatic system, contains position error, velocity error and acceleration error. The use of the derivative of the sliding variable information in control synthesis, who is the case for several second order sliding mode algorithms, implies the need of jerk information, so it is necessary to differentiate the acceleration. In the other hand, in order to reduce the number of sensors used, the velocity cylinder is determined by analog differentiating and low-pass filtering the output of the position and the acceleration information is obtained by differentiating numerically the velocity. It is clear that the use of an algorithm which does not need information about the derivative of the sliding variable is a good solution to find the best performances since one will not differentiate the position three times.

The super twisting algorithm [9][11][12] has been shown to be robust and stable. Moreover it does not requires the time derivative of the sliding variable which in the case of position control of electropneumatic system would involve jerk (derivative of acceleration). For this, the super twisting algorithm is chosen to develop a robust control law for electropneumatic system..

The remainder of the paper is organized as follows: Section 2 presents super twisting algorithm in an informal 
setting. In section 3, a nonlinear model describing the electropneumatic system is presented. The design of a second super twisting controller for this system is derived. Section 4 is devoted to the experimental results. The effectiveness of the proposed super twisting control is verified for the electropneumatic system. Section 5 concludes the paper.

\section{SUPER TWISTING ALGORITHM}

The effective application of sliding mode control to pneumatic systems needs to face the problem related to the chattering phenomenon and the switching control signals. Higher order sliding modes appear to be suitable to counteract this problems[13].

The main idea behind higher order sliding modes is to act on the higher order derivatives of the sliding variable $s$ rather than the first standard sliding modes. Keeping the main advantage of the standard sliding modes, it has the additional advantage that it removes the chattering effect.

The $r^{\text {th }}$ order sliding mode is determined by the equalities $\mathrm{s}=s=\dot{s}=\ddot{s}=\ldots=s^{(r-1)}=0$, which form an $\mathrm{r}$ dimensional condition on the state of the dynamic system. In general, any $r$-sliding controller needs $s, \dot{s}, \ddot{s}, \ldots, s^{(r-1)}$ to be made available, i.e. 2 -sliding controller needs $s, \dot{s}$ to be made available

Super twisting is a 2-sliding algorithm, where the control law does not need any information on the time derivatives of the sliding variable. The super twisting algorithm has been developed and analyzed by Levant in [9].

Consider a system with relative degree one with respect to the input as in (1)

$$
\dot{s}=\phi(s, t)+\psi(s, t) u
$$

In this case, one can write:

$\ddot{s}=a(s, u, t)+b(s, t) \dot{u}$

where,

$$
0<|a(.)| \leq c_{0} \text { and } 0<k_{m} \leq b(.) \leq k_{M}
$$

The super twisting algorithm defines the control law, $u(t)$, as the combination of two terms:

$$
\begin{aligned}
& u_{1}= \begin{cases}-u & |u|>1 \\
-\alpha \operatorname{sign}(s) & |u| \leq 1\end{cases} \\
& \dot{u}_{2}= \begin{cases}-\lambda\left|s_{0}\right|^{\rho} \operatorname{sign}(s) & |s|>s_{0} \\
-\lambda \mid s^{\rho} \operatorname{sign}(s) & |s| \leq s_{0}\end{cases}
\end{aligned}
$$

where $|s| \leq s_{0}$ is called the linearity region and in this set conditions (3) are satisfied. The super twisting algorithm converges in finite time and the corresponding sufficient conditions for finite time convergence are as follows[16]:

$$
\begin{aligned}
& \alpha>\frac{c_{0}}{k_{m}}>0 \\
& \rho\left(\lambda k_{m}\right)^{\frac{1}{\rho}}>\left(k_{M} \alpha+c_{0}\right)\left(2 k_{M}\right)^{\frac{1}{\rho}-2}
\end{aligned}
$$

$$
0<\rho \leq 0.5
$$

Such an algorithm may be efficiently implemented because of its simplicity.

\section{CONTROL DESIGN FOR AN ELECTROPNEUMATIC SYSTEM}

Electropneumatic systems are encountered in a wide range of modern industrial applications because of their relatively small size, light weight, high speed and easy power translation [14].

In literature, the position control has received by far the most attention. However, most of the solutions have been based on the use of PID or the linearization of the nonlinear dynamics, despite the fact that the underlying dynamics are nonlinear with inevitable modeling uncertainties.

Robust control design of the system is another approach that has been followed in previous work. In [15], the sliding mode control (SMC) strategy has been adopted for the control of electropneumatic system. However, chattering in the control action, which is inherent in first order sliding mode, can easily excite high frequency modes. For this a second order sliding mode algorithm is proposed to control the electropneumatic system.

The considered system (Fig. 1) is a linear double acting electropneumatic servo-drive using a single rod controlled by two three-way servo-distributors. The actuator rod is connected to one side of the carriage and drives an inertial load on guide rails. The total moving mass is $17 \mathrm{~kg}$.

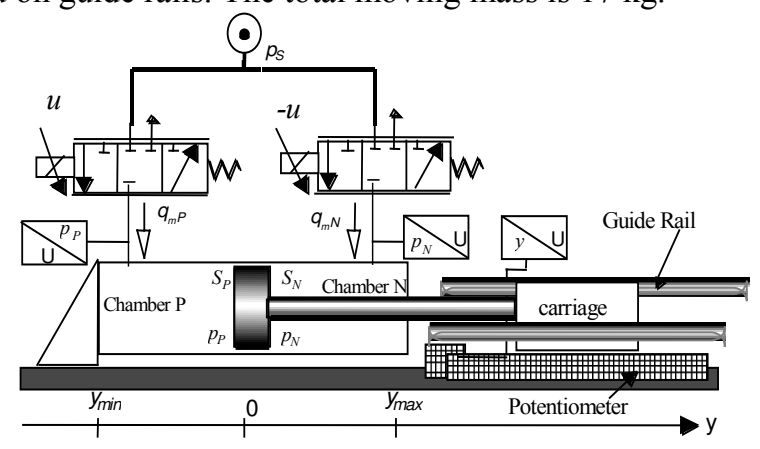

Fig. 1. The electropneumatic system

Table 1 shows the specifications of the pneumatic actuator.

\begin{tabular}{|c|c|}
\hline Diameter of piston & $3.210^{-2}(\mathrm{~m})$ \\
\hline Diameter of rod & $210^{-2}(\mathrm{~m})$ \\
\hline Length of stroke & $0.5(\mathrm{~m})$ \\
\hline Dead volume $\mathrm{V}_{\mathrm{DP}}$ & $10^{-5}\left(\mathrm{~m}^{3}\right)$ \\
\hline Dead volume $\mathrm{V}_{\mathrm{DN}}$ & $1.210^{-5}\left(\mathrm{~m}^{3}\right)$ \\
\hline
\end{tabular}

Table 1 Specifications of the pneumatic actuator

\section{a. Model for control}

The electropneumatic system model can be obtained using three physical laws: the mass flow rate through a restriction, the pressure behavior in a chamber with variable volume and the fundamental mechanical equation. 
In our case, the bandwidth of the Servotronic Joucomatic servodistributor and the actuator are respectively about $200 \mathrm{~Hz}$ and 2,4 Hz. Using the singular perturbation theory, the dynamic of the servodistributors are neglected and his model can be reduced to a static one described by two relationships $q_{m} P\left(u, p_{P}\right)$ and $q_{m} N\left(-u, p_{N}\right)$ between the mass flow rates $q_{m} P$ and $q_{m} N$, the input voltage $u$, and the output pressures $p_{P}$ and $p_{N}$. The pressure evolution law in a chamber with variable volume is obtained assuming the following assumptions [16]: air is a perfect gas and its kinetic energy is negligible. The pressure and the temperature are homogeneous in each chamber. The process is polytropic and characterized by coefficient $\mathrm{k}$. Moreover, the electropneumatic system model is obtained by combining all the previous relations and assuming that the temperature variation is negligible with respect to average and equal to the supply temperature. The only friction regarded was viscous friction

So the following equation gives the model of the above system:

$$
\left\{\begin{array}{l}
\frac{d y}{d t}=v \\
\frac{d v}{d t}=\frac{1}{M}\left[S_{P} p_{P}-S_{N} p_{N}-b v-F_{e x t}\right] \\
\frac{d p_{P}}{d t}=\frac{k r T}{V_{P}(y)}\left[q_{m}\left(u, p_{P}\right)-\frac{S_{P}}{r T} p_{P} v\right] \\
\frac{d p_{N}}{d t}=\frac{k r T}{V_{N}(y)}\left[q_{m}\left(-u, p_{N}\right)+\frac{S_{N}}{r T} p_{N} v\right]
\end{array}\right.
$$

Where:

$$
\left\{\begin{array}{l}
V_{P}(y)=V_{P}(0)+S_{P} y \\
V_{N}(y)=V_{N}(0)-S_{N} y
\end{array}\right.
$$

With:

$$
\left\{\begin{array}{l}
V_{p}(0)=V_{D P}+S_{P} \frac{l_{\text {Stroke }}}{2} \\
V_{N}(0)=V_{D N}+S_{N} \frac{l_{\text {Stroke }}}{2}
\end{array}\right.
$$

are the piping volumes of the chambers for the zero position and $\left.V_{D(P \text { or } N}\right)$ are dead volumes present on each extremities of the cylinder.

The main difficulty for model (8) is to know the mass flow rates $q_{m p}$ and $q_{m N}$. This model is issue of experimental measurement [17][18] and therefore a mathematical model for a static flow stage has been obtained from a polynomial approximation [19] affine in control (equation (11)) and the nonlinear affine model is then given by equation (12):

$$
\left\{\begin{array}{l}
q_{m}\left(u, p_{P}\right)=\varphi\left(p_{P}\right)+\psi\left(p_{P}, \operatorname{sgn}(u)\right) . u \\
q_{m}\left(-u, p_{N}\right)=\varphi\left(p_{N}\right)-\psi\left(p_{N}, \operatorname{sgn}(-u)\right) . u
\end{array}\right.
$$

The nonlinear model of the system has the following form:

$$
\underline{\dot{x}}=f(\underline{x})+g(\underline{x}) \cdot u
$$

where $\underline{x}, f(\underline{x})$ and $g(\underline{x})$ are given by relations

$$
\begin{aligned}
& \underline{x}=\left[\begin{array}{c}
y \\
v \\
p_{P} \\
p_{N}
\end{array}\right] \\
& f(\underline{x})=\left(\begin{array}{c}
v \\
\frac{1}{M}\left[S_{P} p_{P}-S_{N} p_{N}-b v-F_{e x t}\right] \\
\frac{k r T}{V_{P}(y)}\left[\varphi\left(p_{P}\right)-\frac{S_{P}}{r T} p_{P} v\right] \\
\frac{k r T}{V_{N}(y)}\left[\varphi\left(p_{N}\right)+\frac{S_{N}}{r T} p_{N} v\right]
\end{array}\right) \\
& g(\underline{x})=\left(\begin{array}{c}
0 \\
\frac{k \cdot r \cdot T}{V_{P}(y)} \cdot \psi\left(p_{P}, \operatorname{sgn}(u)\right) \\
-\frac{k \cdot r \cdot T}{V_{N}(y)} \cdot \psi\left(p_{N}, \operatorname{sgn}(-u)\right)
\end{array}\right)
\end{aligned}
$$

By using model (12), the aim of this paper is to apply super twisting algorithm (4) to the electropneumatic system while trying to provide a good accuracy in term of position tracking and to avoid the chattering phenomena.

\section{b. Control design}

Let's define the sliding variable as follows:

$$
s=\lambda^{2}\left(y-y_{d}\right)+2 \lambda\left(\dot{y}-\dot{y}_{d}\right)+\left(\ddot{y}-\ddot{y}_{d}\right)
$$

where $\lambda$ is a positive parameter such that $P(x)=\lambda^{2} x+2 \lambda \dot{x}+\ddot{x}$ is Hurwitz polynomial.

$$
\begin{aligned}
s= & \lambda^{2}\left(y-y_{d}\right)+2 \lambda\left(v-\dot{y}_{d}\right) \\
& +\frac{1}{M}\left[S_{P} p_{P}-S_{N} p_{N}-b v-F_{\text {ext }}\right]-\ddot{y}_{d} \\
\dot{s}= & \phi+\psi \times u
\end{aligned}
$$

where:

$$
\begin{aligned}
& \phi= \lambda^{2}\left(v-\dot{y}_{d}\right)+2 \lambda\left(\frac{1}{M}\left[S_{P} p_{P}-S_{N} p_{N}-b v-F_{\text {ext }}\right]\right. \\
&\left.-\ddot{y}_{d}\right)+\frac{k r T}{M}\left[\frac{S_{p}}{V_{p}(y)} \varphi\left(p_{p}\right)-\frac{S_{N}}{V_{N}(y)} \varphi\left(p_{N}\right)\right. \\
&\left.-\frac{v}{r T}\left(\frac{S_{p}^{2} p_{P}}{V_{P}(y)}+\frac{S_{N}^{2} p_{N}}{V_{N}(y)}\right)\right]-\frac{b}{M^{2}}\left(S_{P} p_{P}-S_{N} p_{N}\right. \\
&\left.-b v-F_{e x t}\right)-\dddot{y}_{d}=\phi_{0}+\delta \phi \\
& \psi=\frac{S_{P}}{M} \frac{k r T}{V_{P}(y)} \psi\left(p_{P}, \operatorname{sgn}(u)\right) \\
&+\frac{S_{N}}{M} \frac{k r T}{V_{N}(y)} \psi\left(p_{N}, \operatorname{sgn}(-u)\right)
\end{aligned}
$$


with

$$
\begin{aligned}
& \phi_{0}=\lambda^{2}\left(v-\dot{y}_{d}\right)+2 \lambda\left(\frac{1}{M}\left[S_{P} p_{P}-S_{N} p_{N}-F_{\text {ext }}\right]\right. \\
& \left.-\ddot{y}_{d}\right)-\frac{k r T}{r T M}\left[\left(\frac{S_{p}^{2} p_{P} v}{V_{P}(y)}+\frac{S_{N}^{2} p_{N} v}{V_{N}(y)}\right)\right]-\dddot{y}_{d}
\end{aligned}
$$

and

$$
\begin{aligned}
& \delta \phi=-2 \lambda \frac{b}{M} v+\frac{k r T}{M}\left[\frac{S_{p}}{V_{p}(y)} \varphi\left(p_{p}\right)-\frac{S_{N}}{V_{N}(y)} \varphi\left(p_{N}\right)\right] \\
& -\frac{b}{M^{2}}\left(S_{P} p_{P}-S_{N} p_{N}-b v-F_{\text {ext }}\right)
\end{aligned}
$$

$\phi_{0}$ is the known nominal expression whereas the expressions $\delta \phi$ contain all the uncertainties, i.e., $\varphi\left(p_{p}\right)$, $\varphi\left(p_{N}\right)$ and $b$. The final controller is composed by a linearizing controller coupled to a super twisting algorithm Using the static feedback:

$$
\begin{aligned}
& u=\psi^{-1}\left[-\phi_{0}+v\right] \\
& \text { one obtains: } \\
& \dot{s}=\delta \phi+v
\end{aligned}
$$

There exist a positive constant $c_{0}$, so that: $0<|\delta \dot{\phi}().| \leq c_{0}$

The super twisting algorithm defines the control law, $v(t)$, as the combination of two terms.

$$
\begin{aligned}
& v=v_{1}+v_{2} \\
& v_{1}=-\alpha \operatorname{sign}(s) \\
& \dot{v}_{2}= \begin{cases}-\lambda\left|s_{0}\right|^{\rho} \operatorname{sign}(s) & |s|>s_{0} \\
-\lambda|s|^{\rho} \operatorname{sign}(s) & |s| \leq s_{0}\end{cases}
\end{aligned}
$$

with

$$
\begin{aligned}
& \alpha>c_{0}>0 ; \\
& \rho \lambda^{\frac{1}{\rho}}>2^{\frac{1}{\rho}-2}\left(\alpha+c_{0}\right) \\
& 0<\rho \leq 0.5
\end{aligned}
$$

The relative order of the position output of the electropneumatic system is three. This means that there are "three integrators" between the control input of the system and the output, which is the cylinder piston position:

- This is why the validity of the control law depends on the stability of the unobservable subsystem, which is one-dimensional. It is very difficult to obtain results about the global stability of the zero dynamics, but, in the physical domain, the local stability has been proved [20].

- This means also that the electropneumatic system can only track position trajectories at least three times differentiable. The desired trajectory has been carefully chosen in order to respect the differentiability required.

\section{EXPERIMENT RESULTS}

This controller was implemented using a dSpace DS1104 controller board with a dedicated digital signal processor. The sensed signals, all analog, were run through the signal conditioning unit before being read by the A/D.
The velocity cylinder is determined by analog differentiating and low-pass filtering the output of the position. However, the accelerometer sensor is not used because of its cost. The acceleration information is therefore obtained by differentiating numerically the velocity.

The aim of the control law is to respect a good accuracy in term of position tracking for a desired trajectory defined by a fifth order polynomial function (Fig. 2). The amplitude of displacement is equal to $50 \%$ of the total stroke around the central position, i.e. the total displacement is equal to $500 \mathrm{~mm}$. The maximum desired velocity is equal to 0.60 $\mathrm{m} / \mathrm{s}$. The test have been made several times in the aim to see the repeatability of the experimental results. Some experiment results are provided here to demonstrate the effectiveness of the super twisting controller.

The robust control characteristics of this controller can be observed. Indeed, as is shown in Fig. 3, In steady state, the position error is about $70 \mu \mathrm{m}$ and the maximum position tracking error is about $0.7 \mathrm{~mm}$, so this control law seems more interesting that feedback linearization [21].

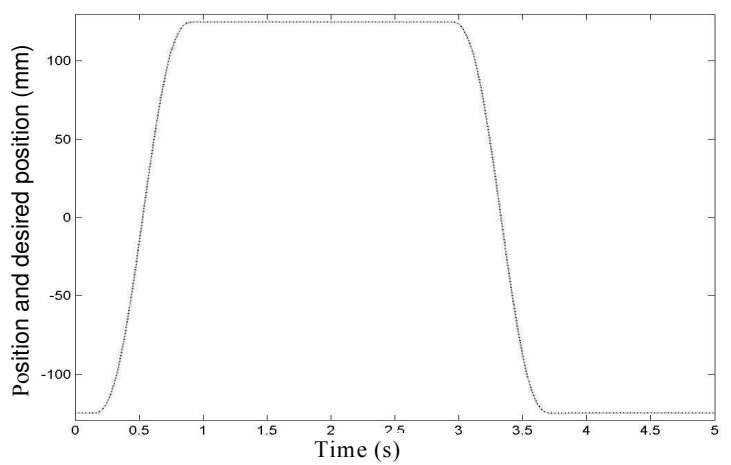

Fig. 2: Real and desired position ( $\mathrm{mm})$

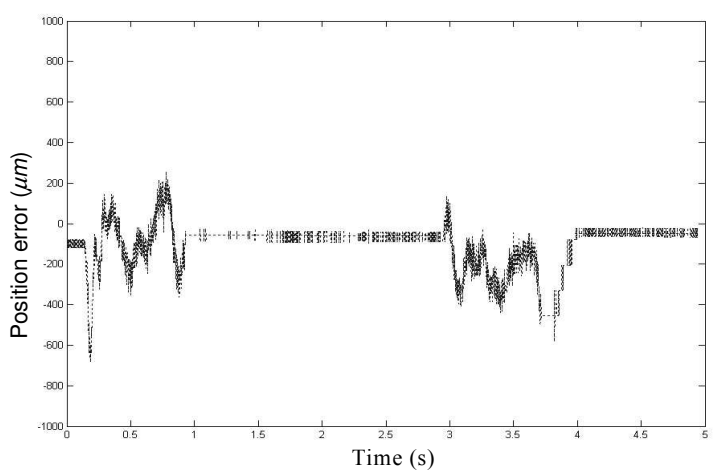

Fig.3: Position error (mm)

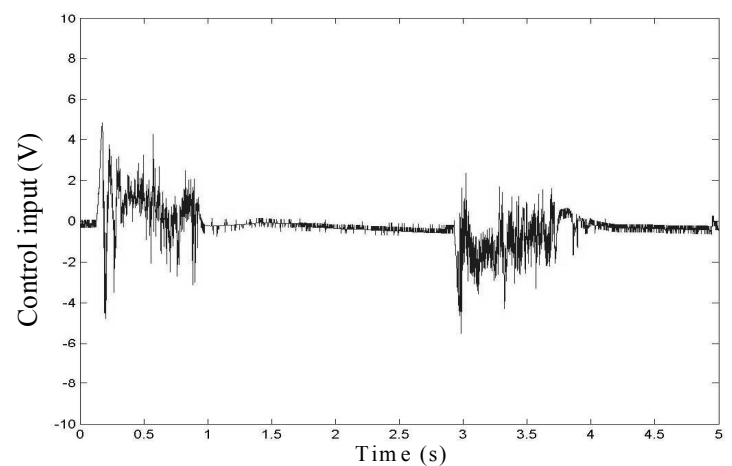

Fig.4: Control input (V) 
Fig. 4 shows that the control signal is not influenced by the chattering effect.

A first order sliding mode controller is synthesized and applied to the electropneumatic system. As is shown in Fig. 5 , the chattering phenomenon occurs and this reduces the performance of the controller. The chattering phenomenon is a bad property from an energetically efficient point of view. Indeed, when the control signal increases, supply energy is used. And when the control signal decreases, the pneumatic energy approaches the exhaust. So the control signal oscillations lead to inefficiency. Moreover, there is a noise that can be heard during the experiment

So by comparing the super twisting control law with that obtained by fist order sliding mode (see also [15] [22]), super twisting controller seems more satisfactory lifetime of components and consumption of energy.

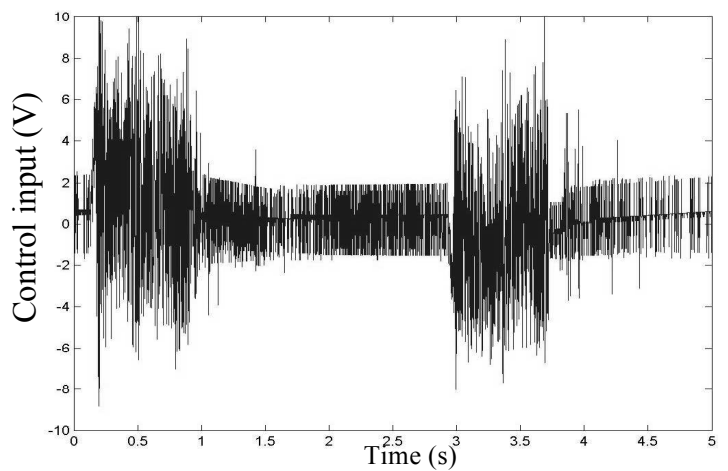

Fig.5: Control input (V)

To illustrate the convergence of the super twisting algorithm, the initial position is set at $75 \mathrm{~mm}$. The algorithm is employed when the desired position reaches $120 \mathrm{~mm}$ (see Fig. 6).

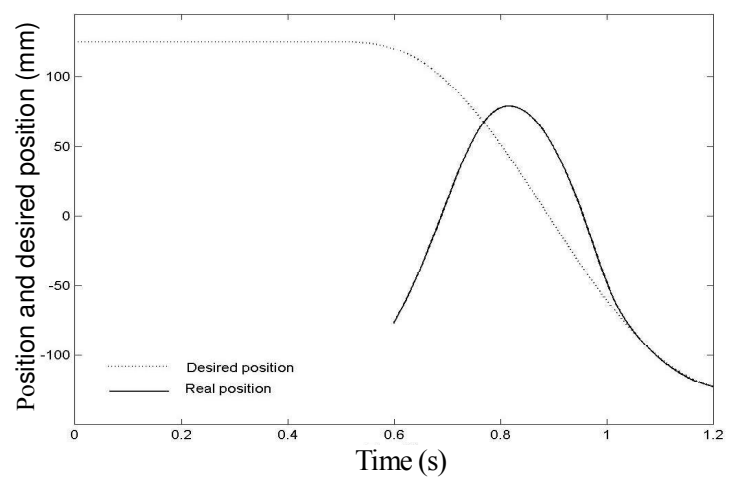

Fig.6: Real and desired position (mm)

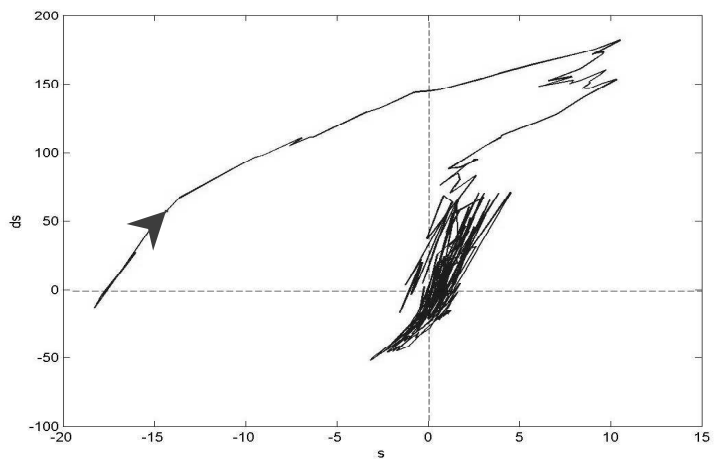

Fig.7: Phase trajectory
Fig. 7 show the trajectories of the super twisting algorithm. The trajectories of the super twisting algorithm are characterized by twisting around the origin on the phase portrait of sliding variable.

\section{CONCLUSION}

The robustness of 2-sliding controller (super twisting algorithm) in the presence of practical engineering constraints and realities is guarantied. Experimental results show that the trajectory tracking is done with a very good accuracy. Moreover, and contrary to the other algorithms, the super twisting algorithm does not need any information on the time derivative of the sliding variable, i.e., in our case, this algorithm does not need any information on the jerk (derivative of acceleration).

\section{REFERENCES}

[1] J. J. E. Slotine and W. Li “ Applied Nonlinear Control” Prentice-Hall $1991461 \mathrm{p}$.

[2] J.J. Slotine, "Sliding mode controller design for nonlinear systems", International Journal of Control, vol.40, no.2, ,1984, pp.421-434.

[3] V.I. Utkin, "Variable structure systems with sliding modes", IEEE Trans. Automat. Control, vol.26, no.2, 1977, pp. 212-222.

[4] V.I. Utkin, Sliding Mode in Control and optimization, Springer-Verlag, Berlin, 1992.

[5] K. Young, V. I. Utkin, U. Ozguer “A control engineer's guide to sliding mode control" Trans. Automat. Control, vol. 7, no.3, 1999, pp.328-342.

[6] G. Bartolini, A. Ferrara, A. Pisano, and E. Usai, "On the convergence properties of a 2-sliding control algorithm for nonlinear uncertain systems", International Journal of Control, vol. 74, n. 7, 2001, pp. 718-731.

[7] G. Bartolini, A. Pisano, and E. Usai, "Digital Second Order Sliding Mode Control for Uncertain Nonlinear Systems" Automatica vol. 37, no. 9, 2001, pp. 1371-1377.

[8] G. Bartolini, A. Pisano, and E. Usai "Second Order Sliding Mode Control for Container Cranes" Automatica, vol. 38, 2002, pp. 17831790.

[9] A. Levant, "Sliding order and sliding accuracy in sliding mode control", International Journal of Control, vol.58, no.6, 1993, pp.1247-1263.

[10] A. Levant, "Universal SISO sliding-mode controllers with finite-time convergence" IEEE Transaction on Automatic Control 46(9), 2001, pp. 1447-1451.

[11] M. Khan, S. Spurgeon, and P. Puleston " Robust speed control of an automotive engine using second order sliding modes” European Control Conference ECC'01, 2001, pp. 974-978.

[12] M. Khan, S. Spurgeon, P. Puleston and A. Levant " Simple outputfeedback 2-sliding controller for systems of relative degree two " European Control Conference ECC'03, 2003

[13] G. Bartolini, A. Ferrara, and E. Usai, "Chattering avoidance by second-order sliding mode control", IEEE Trans. Automat. Control, vol. 43, no.2, 1998, pp.241-246.

[14] K.A. Edge, "The control of fluid power systems responding to the challenge" Journal of Systems and Control Engineering, Vol. 211, $\mathrm{N}^{\circ} 12,1997$, pp. 91-110.

[15] M. Bouri and D. Thomasset, "Sliding Control of an Electropneumatic Actuator Using an Integral switching Surface”. IEEE. Transaction on control systems technology. Vol. 9 No. 2, 2001, pp.368-375

[16] J.L. Shearer, "Study of pneumatic processes in the continuous control of motion with compressed air" Parts I and II. Trans. Am. Soc. Mech. Eng., Vol. 78, 1956, pp. 233-249.

[17] X. Brun, S. Sesmat, D. Thomasset and S. Scavarda, "A comparative study between two control laws of an electropneumatic actuator" 
European Control Conference ECC'99 Karlsruhe, [CD Rom], reference F1000-5. 1999

[18] S. Sesmat and S. Scavarda, "static characteristics of a three way servovalve" In: $12^{\text {th }}$ Aachen Conference on Fluid Power Technology, Aachen, Germany, March 12-13, 1996, pp. 643-652.

[19] M. Belgharbi, D. Thomasset, S. Scavarda and S. Sesmat, "Analytical model of the flow stage of a pneumatic Servodistributor for simulation and nonlinear control" In the Sixth Scandinavian International Conference on Fluid Power, SICFP'99, Tampere, Finland, 1999, pp. 847-860.

[20] X. Brun, M. Belgharbi, S. Sesmat, D. Thomasset, and S. Scavarda, "Control of an electropneumatic actuator, comparison between some linear and nonlinear control laws", Journal of Systems and Control Engineering, vol.213, no.I5, (1999), pp.387-406.

[21] X. Brun, D. Thomasset and E. Bideaux, "Influence of the process design on the control strategy: application in electropneumatic Field" Control Engineering Practice, 2002, pp.727-735.

[22] F.-J Lin, R.-F. Fung and R.-J Wai, "Comparison of sliding-Mode and Fuzzy Neural Network Control for motor-Toggle Servomechanism" IEEE/ASME Transactions on Mechatronics vol. 3 , no. 4, 1998, pp 302-318 